\title{
Minimal Invasive Modality for Full Rehabilitation of Edentulous Mandible with One-Piece Implants in Elderly Patients; A Case Report
}

\author{
Henri Diederich* \\ Dental Clinic Henri Diederich, UK
}

Submission: March 28, 2018; Published: April 11, 2018

*Corresponding author: Henri Diederich, Dental Clinic Henri Diederich, Luxembourg, UK, Tel: +352621144664; Email: hdidi@pt.lu

\author{
Abstract \\ One-piece implants encourage the use of minimally invasive surgical techniques in restoring edentulous spaces with minimal postoperative \\ discomfort and excellent implant survival rate.
}

The compressive one-piece implant can be used for multiple unit restorations with immediate loading in the upper and lower jaws. It can also be used in combination with a conventional implant and it can be placed flapless.

The presented case reports offering a treatment modality and procedure of mandibular rehabilitation involving the functional restoration of a mandibular fully edentulous patient with minimal invasive surgical technique with one-piece implant in elderly patients.

Keywords: One-piece Implants; Edentulous patient; Rehabilitation; Flapless surgery; Minimal invasive technique

\section{Introduction}

The use of conventional implants in the rehabilitation of edentulous space has been discussed extensively in the literature [1-4]. However, conventional implant systems may be limited or inapplicable in restoring some edentulous spaces due to various anatomical reasons. One of such reason is insufficient space between adjacent edentulous teeth for the use of a conventional implant which makes implant placement impossible [4,5-7]. In these situations, an alternative implant system for the restoration of such cases is required.

The One-Piece implants help in restoring edentulous spaces that previously cannot be restored with conventional implants; it also encourages the use of minimally invasive surgical techniques which encourage maximum tissue preservation $[8,9]$.

One-Piece implant offers a unique monobloc design that integrates both implant and superstructure, for a quick, simple one-stage procedure. Implants are specifically engineered for use in narrow ridges and tight spaces [10]. They are time effective as they eliminate the need for second stage surgery, mucosal healing period, and decrease patient exposure to additional pain and discomfort. The innovative geometries and advanced surface morphology of the implant offer high initial stability $[11,12]$. One Piece implants are less invasive and can be immediately loaded in case of good bone quality, or progressively loaded in case of less than ideal bone quality.

One Piece implant provides simple treatment sequence at lower cost and it offers the possibility to treat elderly people for example with minimal invasive implant placement (Flapless implant surgery) technique.

Flapless implant placement technique otherwise called minimally invasive procedure can be performed free hand, by using guided surgery or custom fabricated surgical guides made of casts taken at the first patient visit. This procedure, when applicable, provides patients and doctors with another treatment approach. Several clinical papers reported excellent short- and long-term survival rates (of about $98.7 \%$ at 2 years) for implants placed using flapless or minimally invasive approaches with the option of delivering immediately a pre-fabricated temporary prosthesis $[13,14]$.

In term of implant prosthodontics, technical complexity is minimized with One-Piece implants by reducing the number of components required, which also means that less treatment time is required. Patients benefit from having implants placed flapless and loaded immediately [14-16]. 
The following case report describes procedures where OnePiece implants were used to rehabilitate severely atrophied edentulous mandible in an elderly patient.

\section{Case Presentations}

Patient is a 91-year-old patient with an ill-fitted removable prosthesis who was not happy with her prosthesis and wanted an improved treatment modality in the mandible. Patient's family was afraid of implant placement because of the age of the patient. Following complete medical examination, patient was found to be in a good health \& after clinical examination; the possibility of implants treatment was discussed (Figure 1).

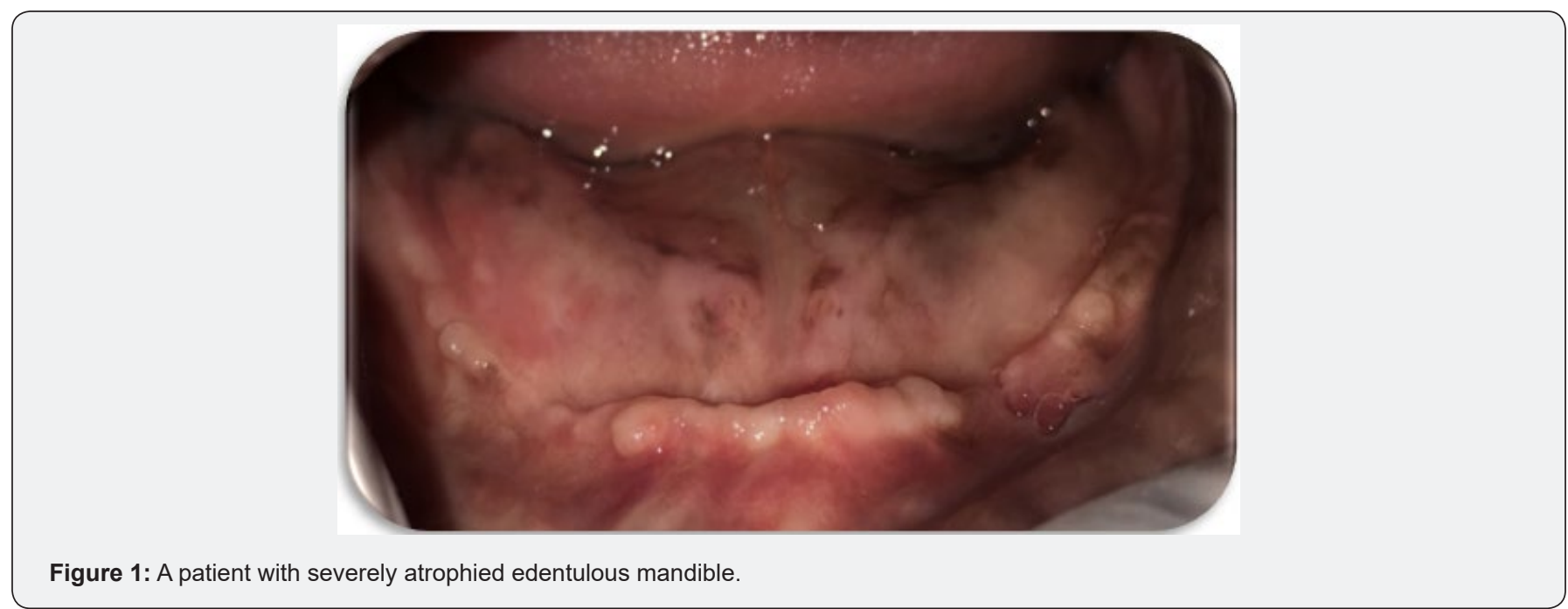

At the first appointment, A CBCT radiograph was taken to be satisfactory, as follows; check if there was enough bone for implant placement, found to

\section{Patient imaging and case planning (Figure 2)}

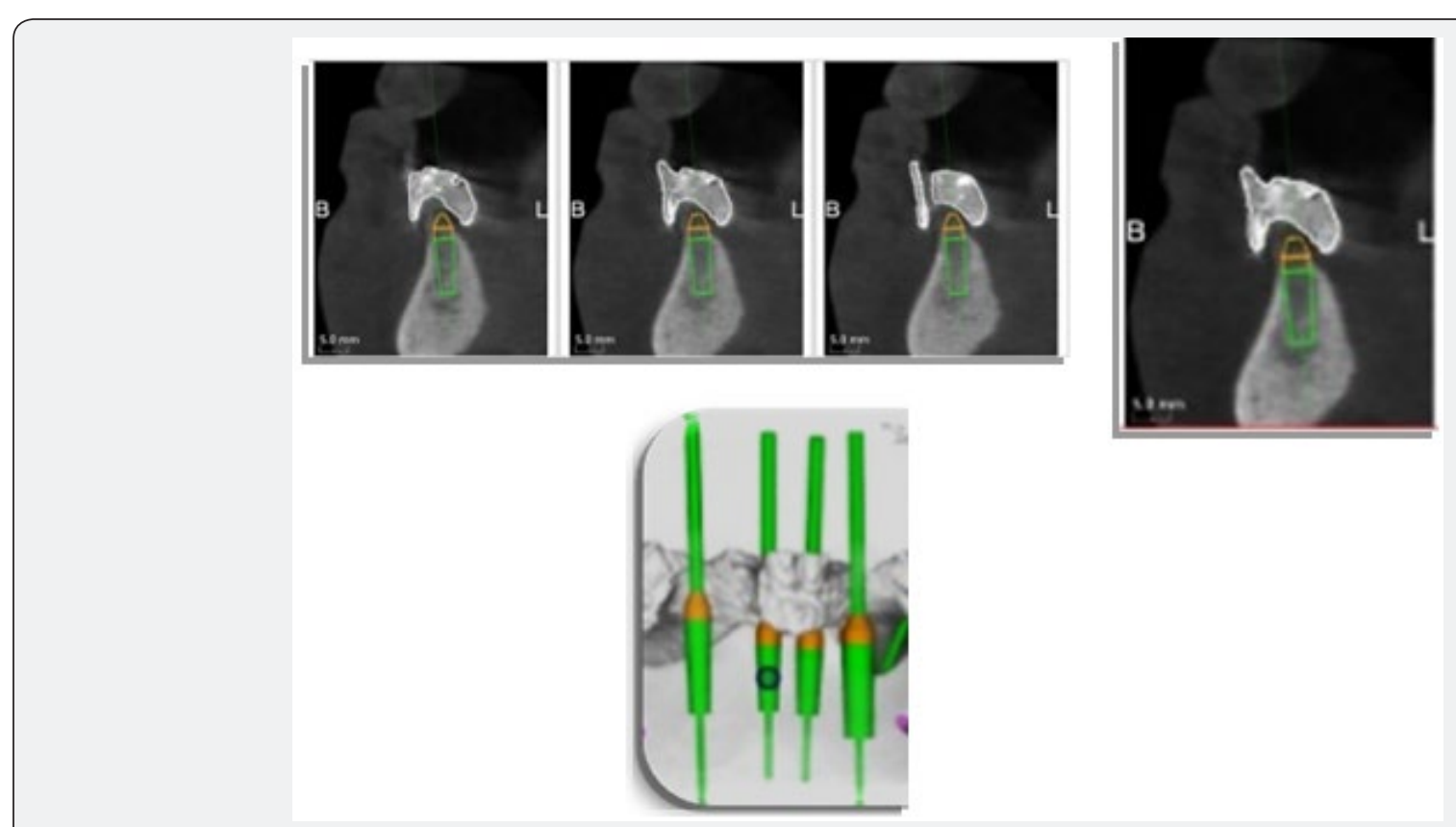

Figure 2: Pre-operative Virtual Planning.

a) Duplication of the mandibular complete denture was encountered utilizing a radio-opaque material to construct radiographic stents for the patient.

b) Patient was imaged using cone beam computed tomography scans (CBCT scans) through a cone beam CT machine (CBCT, i-CAT Vision)*. Each patient was instructed to bite on a piece of cotton to achieve adequate jaw separation. Finally, the resultant image was obtained as a DICOM file.

c) The images were processed using specialized image processing software (Blue Sky implant software)**.

d) Virtual implants were placed in the planned positions of available bone. Then, a solid block was modelled \& guiding 
holes denoting the implant direction were opened into the block.

a. The surgical stent was sterilized chemically*** to be used during surgery.

b. The patient was instructed to take a prophylactic antibiotic preoperatively**** and to rinse with chlorohexidine mouth wash ${ }^{* * * * *}$ four hours before surgery.

*Imaging Sciences International, Hatfield, Pa, USA.

** Blue Sky Bio, LLC

***Micro 10, A.B. Pharma.

****Augmentin 625mg Beecham, MUP.

*****Listerine mouthwash, USA.

\section{Surgical procedures}

a) The entire surgical armamentarium was autoclaved.

b) The surgical places as well as the circumoral tissues were

also disinfected by wiping them with antiseptic solution*. c) Using 4\% articaine anaesthetic solution**, Buccal \& Lingual infiltration anaesthesia was applied.

d) Osteotomy sites for the implants were performed using a pilot drill of $2 \mathrm{~mm}$ diameter \& a final drill for coronal flaring.

\section{Implant insertion}

a) The sterile box of the implant*** was unwrapped, and then the inner vial was also opened \& the implant osteotomy was washed thoroughly using sterile saline solution.

b) The sterile implant was introduced into its site by screwing it using moderate finger pressure [self-tapping] once resistance was felt, the ratchet wrench was adapted to the abutment and the screwing process was continued.

one-piece implants of $3,5 \mathrm{~mm}$ diameter and $14 \mathrm{~mm}$ length were inserted flapless in positions 31, 32, 41 and 42 with a torque of $50 \mathrm{~N}$. One Piece implants (Figure 3 ) are machined in grade 23 titanium with a hydroxyapatite/beta tricalcium phosphate surface (HA/BTCP), the implant can be used to create single restorations in situations where high primary stability is achieved on placement.
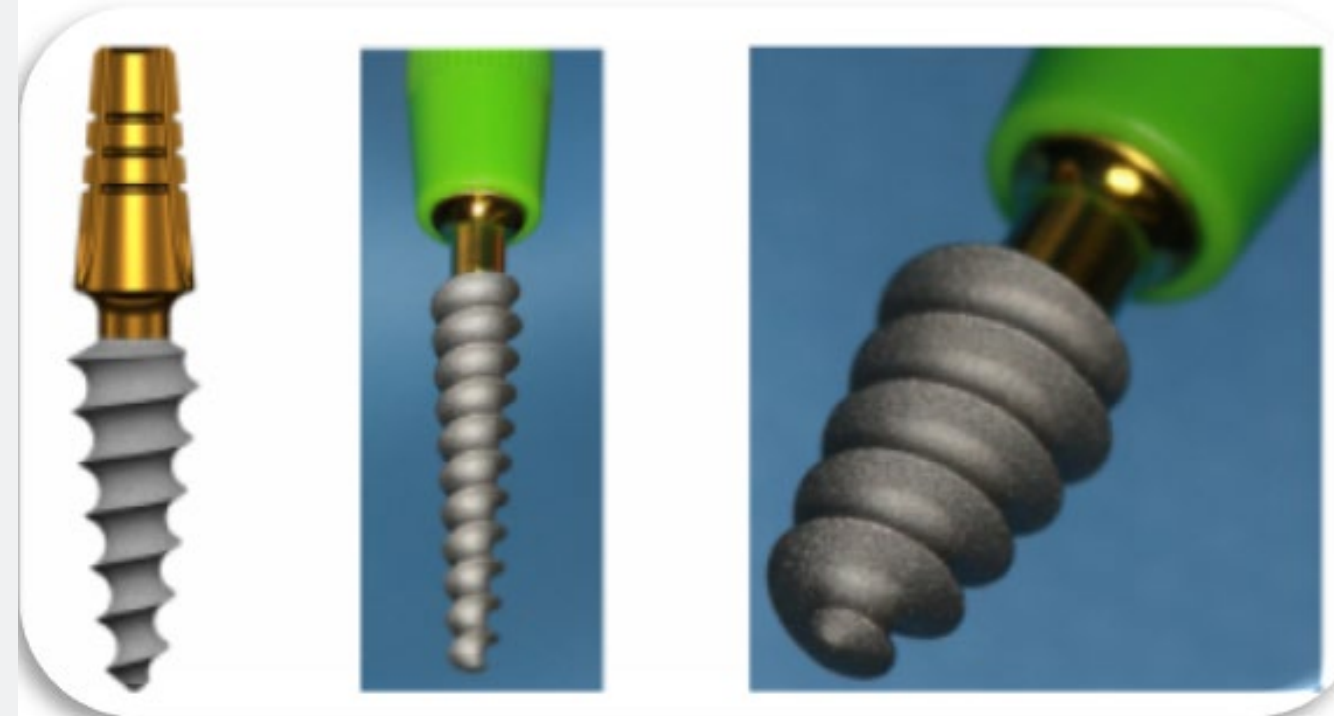

Figure 3: one-piece implant with a compression thread.

The axial implants are generally intended for the anterior part of the mandible or the maxilla where there is sufficient bone height. They allow bi-cortical or even tricortical anchorage and provide good stability, even in medium-dense bone.

*Listerine mouthwash, USA

**Ubestesin, 3M ESPE, Germany.

***ROOTT Compressive Dental Implant, TRATE AG, Switzerland.

\section{Restorative procedures}

a) After the implant placement, an addition silicone impression was taken, and bite registration was made in the usual manner.

b) After completing Try-in stage and receiving the final prosthesis from the laboratory, bar was cemented, and the lower prosthesis was delivered. (Figure 4 \& 5) Then, a postoperative Panoramic radiograph was made to verify accurate treatment plan (Figure 6). 


\section{Advances in Dentistry \& Oral Health}

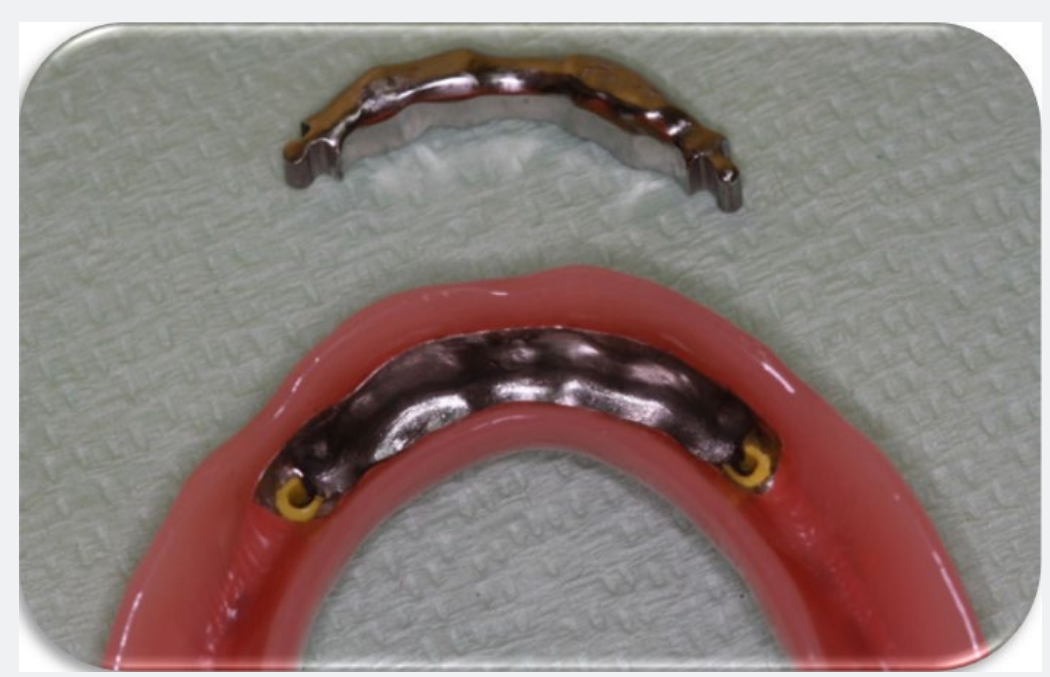

Figure 4: Bar-retained Overdenture Prosthesis.
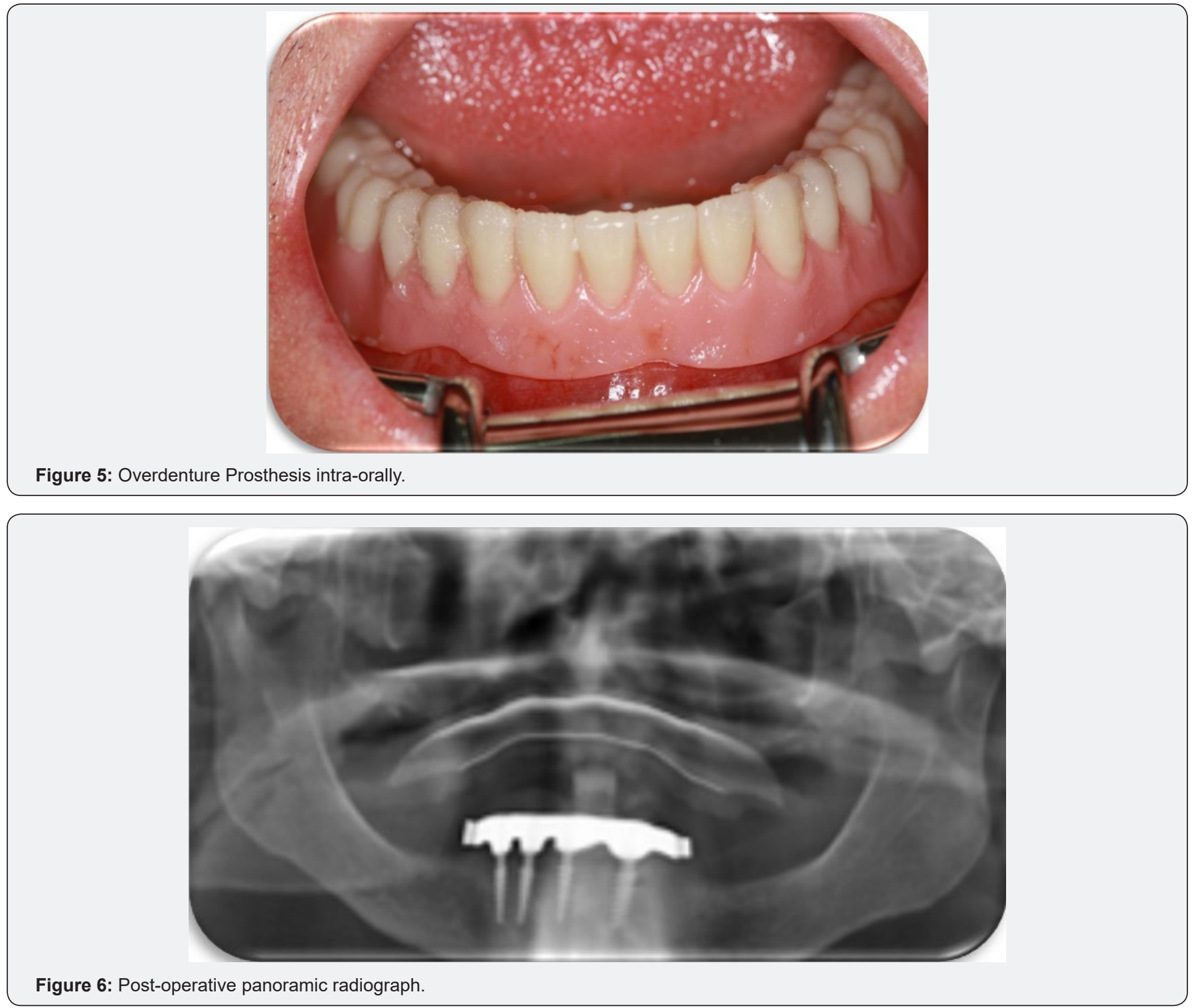


\section{Post-operative follow-up Phase: (Figure 7)}

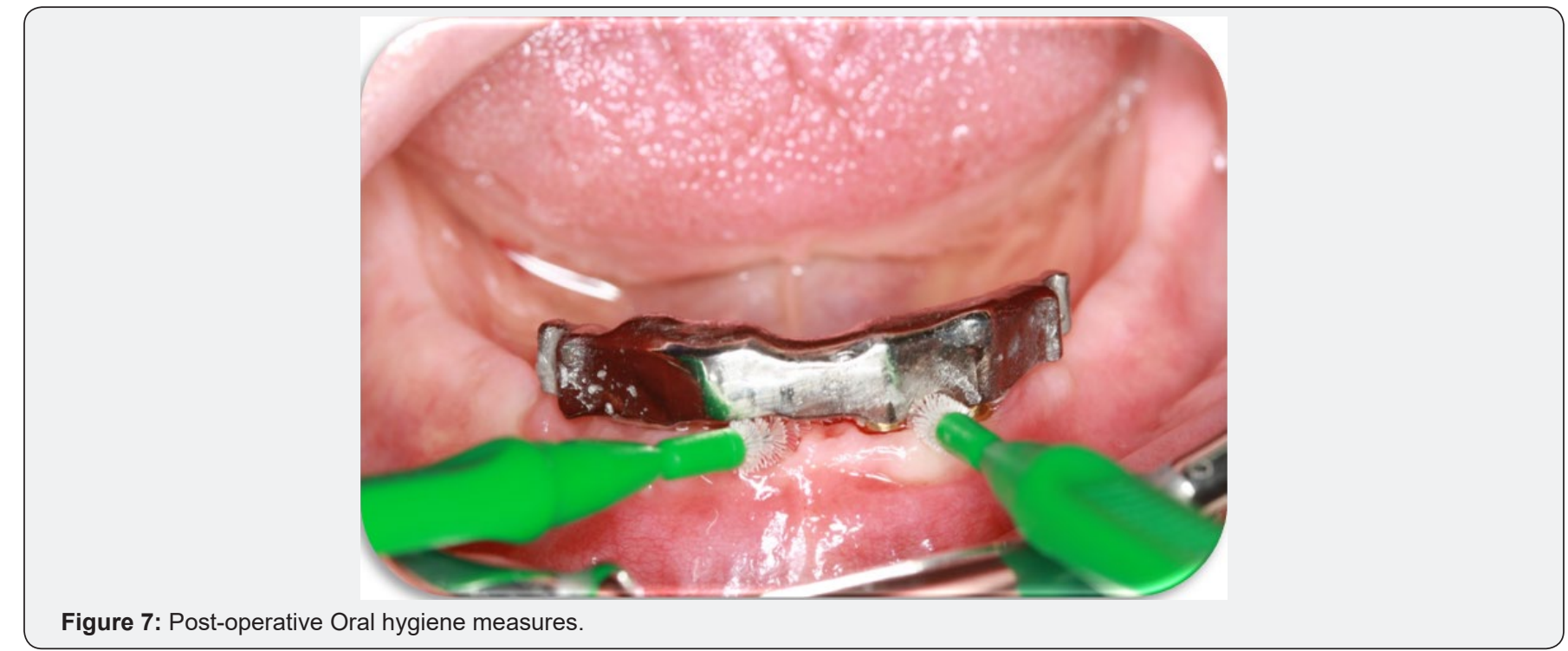

The patient was seen for follow-up and oral hygiene measures as well as measuring patient's satisfaction every single week for the first three months, then every 6 months for the following 5 years of assessment.

\section{Discussion}

One-Piece implants facilitate oral rehabilitation and accelerate tooth replacement procedure [8,17]. The implant permits minimally invasive surgical techniques with a simpler treatment sequence at lower costs [12].

When compared to conventional implants, One Piece implants are cost-effective, they eliminate the need for cover screws, healing abutments, subsequent separate implant attachments or separate implant abutments [12,17].

In the above cases, One Piece implants (TRATE.AG, ROOTT.ch, compressive implants) were used. These are single component implants with a compression thread. The special compressive thread produces compression when inserted into the cancellous bone, thereby creating a layer of cortical bone around the implant which allows immediate loading with high primary stability. The abutment direction on the implant can be adjusted up to $15^{\circ}$ relative to the implant axis.

The compressive One-Piece implant can be used to restore single crowns and anterior cemented bridges, or multiple unit restorations with immediate loading in the upper and lower jaws with adequate bone tissue. It can also be used in combination with a conventional implant and it allows flap and flapless placement. The implants insertion is like that of crestal implants, with a recommended minimum torque of $35 \mathrm{~N} / \mathrm{cm}$.

\section{Conclusion}

The presented case reports show the functional restoration of an edentulous patient with minimal invasive surgical technique with One Piece implant in elderly patients. Rehabilitation of seemingly difficult edentulous cases was achieved within a short period of time.

\section{Conflict of Interest}

This clinical study was self-funded by the authors, with no conflict of interest.

\section{References}

1. Ali SA, Karthigeyan S, Deivanai M, Kumar A (2014) Implant rehabilitation for atrophic maxilla: a review. J Indian Prosthodont Soc 14(3): 196-207.

2. Belser UC, Buser D, Hess D, Schmid B, Bernard JP, et al. (2000) Aesthetic implant restorations in partially edentulous patients--a critical appraisal. Periodontol 17: 132-150.

3. Bidra AS (2011) Three-dimensional esthetic analysis in treatment planning for implant-supported fixed prosthesis in the edentulous maxilla: review of the esthetics literature. J Esthet Restor Dent 23(4): 219-236.

4. Mericske-Stern RD, Taylor TD, Belser U (2000) Management of the edentulous patient. Clin Oral Implants Res 11 Suppl 1: 108-125.

5. Bosse LP, Taylor TD (1998) Problems associated with implant rehabilitation of the edentulous maxilla. Dent Clin North Am 42(1) : 117-127.

6. Candel E, Penarrocha D, Penarrocha M (2012) Rehabilitation of the atrophic posterior maxilla with pterygoid implants: a review. J Oral Implantol 38(S1): 461-466.

7. Candel-Marti E, Carrillo-Garcia C, Penarrocha-Oltra D, PenarrochaDiago M (2012) Rehabilitation of atrophic posterior maxilla with zygomatic implants: review. J Oral Implantol 38(5): 653-657.

8. Lauritano D, Grassi R, di SD, Lucchese A, Petruzzi M (2014) Successful mandible rehabilitation of lower incisors with one-piece implants. J Med Case Rep 8: 406.

9. Markwardt J, Weber T, Modler N, Sembdner P, Lesche R, et al. (2014) One vs. two piece customized implants to reconstruct mandibular continuity defects: a preliminary study in pig cadavers. J Craniomaxillofac Surg 42(6): 790-795.

10. Wu AY, Hsu JT, Chee W, Lin YT, Fuh LJ, et al. (2016) Biomechanical evaluation of one-piece and two-piece small-diameter dental implants: 
In-vitro experimental and three-dimensional finite element analyses. J Formos Med Assoc 115(9): 794-800.

11. Jung RE, Grohmann P, Sailer I, Steinhart YN, Fehér A, et al. (2016) Evaluation of a one-piece ceramic implant used for single-tooth replacement and three-unit fixed partial dentures: a prospective cohort clinical trial. Clin Oral Implants Res 27(7): 751-761.

12. Rajput N, K P S, G R, S C C, Mohammed J (2013) Minimally invasive transmucosal insertion and immediate provisonalization of one-piece implant in partially edentulous posterior mandible. J Clin Diagn Res 7(9): 2070-2073.

13. Barrachina-Diez JM, Tashkandi E, Stampf S, Att W (2013) Longterm outcome of one-piece implants. Part II: Prosthetic outcomes. A systematic literature review with meta-analysis. Int J Oral Maxillofac Implants 28(6): 1470-1482.

14. Pozzi A, Polizzi G, Moy PK (2016) Guided surgery with tooth-supported templates for single missing teeth: A critical review. Eur J Oral Implantol 9 Suppl 1: S135-S153.
15. Cannizzaro G, Leone M, Consolo U, Ferri V, Esposito M (2008) Immediate functional loading of implants placed with flapless surgery versus conventional implants in partially edentulous patients: a 3-year randomized controlled clinical trial. Int J Oral Maxillofac Implants 23(5): 867-875.

16. Furhauser R, Mailath-Pokorny G, Haas R, Busenlechner D, Watzek G, et al. (2015) Esthetics of Flapless Single-Tooth Implants in the Anterior Maxilla Using Guided Surgery: Association of Three-Dimensional Accuracy and Pink Esthetic Score. Clin Implant Dent Relat Res 17 Suppl 2: e427-e433.

17. Wang QN, Li M, Qiu J, Zhang XZ3, Wu ZQ4, Chen DL, et al. (2015) [Application of one-piece implant-supported detachable telescope retained fixed bridge in edentulous cases]. Shanghai Kou Qiang Yi Xue 24(6): 702-707.

\section{Your next submission with Juniper Publishers will reach you the below assets}

- Quality Editorial service

- Swift Peer Review

- Reprints availability

- E-prints Service

- Manuscript Podcast for convenient understanding

- Global attainment for your research

- Manuscript accessibility in different formats

( Pdf, E-pub, Full Text, Audio)

- Unceasing customer service

Track the below URL for one-step submission https://juniperpublishers.com/online-submission.php 
